\title{
El derecho a la identidad y su relación con el art. 579 del CCyC
}

Ana Lis Palacios

\section{Introducción}

Tal como ha sido justificado reiteradamente por los integrantes de la comisión redactora y es de público conocimiento, el Código Civil y Comercial (Ley N $\left.{ }^{0} 26994\right)^{1}$ contiene un sinnúmero de normas procesales. Especialmente en materia de derecho de familia, existe un capítulo dedicado a los "procesos de familia" en general y, a su vez, al regular cada instituto, establece reglas procesales específicas. No obstante las distintas opiniones existentes sobre las ventajas y desventajas de tal inclusión de normas procesales, lo cierto es que en determinados temas se puede asumir una actitud crítica de tales preceptos a la luz del nuevo paradigma de los derechos humanos con reconocimiento internacional.

En este trabajo, se procederá a analizar -sin pretender agotar tan vasta temática- el derecho humano a la identidad, sus caracteres e implicancias particularmente en relación al instituto de la filiación. Asimismo, se analizarán las normas procesales civiles y penales relativas a la prueba científica de ácido desoxirribonucleico (A.D.N.) y a los modos de su obtención, para luego evaluar si las mismas son compatibles con el nuevo paradigma mencionado y si permiten el ejercicio real y efectivo de los derechos de las personas.

En ese sentido, podremos analizar con actitud crítica las normas procesales involucradas y evaluar si las mismas respetan o no la constitución nacional y los tratados internacionales vigentes sobre derechos humanos.

Sancionada el 1/10/2014, y entró en vigencia el 1 de agosto de 2015. En adelante CCyC. 


\section{Conceptualización de derecho a la identidad}

La identidad personal es la cualidad que permite a cada cual ser uno mismo y no otra persona y a ser considerado como realmente es. En función de ella, los integrantes de una comunidad pueden conocer a esa persona, como ser humano único e irrepetible, con esos rasgos de personalidad propios.

Así, la Corte Suprema de Justicia de la Nación (en adelante CSJN), en el fallo Muller, el Dr. Petracchi en el considerando $12^{\circ}$ de su voto expresó: "La identidad es representada como un verdadero y propio derecho personalísimo cuyo contenido está delimitado (...) por tener el sujeto caracteres propios, que lo hacen diverso a los otros e idéntico sólo a sí mismo"2.

Ahora bien, es de resaltar que este derecho -así como sus derivados-, han tenido una importantísima evolución en los últimos años y se le ha reconocido una creciente relevancia, particularmente en el campo del derecho filial. Ello se debe a varios factores entre los cuales pueden señalarse el otorgamiento de jerarquía constitucional a los tratados internacionales de derechos humanos (artículo 75 inciso 22, conforme a la constitución reformada en el año 1994), pero fundamentalmente a la propia historia e idiosincrasia de nuestro país.

El derecho humano a la identidad es, en primer lugar, uno de los derechos implícitos protegidos por el artículo 33 de la Constitución Nacional. Pero además de ello, tal como se mencionara, el Sistema Universal de los Derechos Humanos reconoce este derecho a la identidad tanto en la Convención Americana sobre Derechos Humanos (artículo 18), como en el Pacto Internacional de Derechos Civiles y Políticos (art. 24) y la Convención de los Derechos del Niño (artículos. 7 y 8). A su vez, dicha normativa internacional ha tenido repercusión en la legislación interna, especialmente en la Ley 26.061 y su decreto reglamentario 415/2006 que receptan, entre otras garantías, la inmediata identificación e inscripción en un registro (Registro

2 "Muller, Jorge s/denuncia", 13/11/1990, AbeledoPerrot, JA 1990-IV-574. 
de Estado Civil y Capacidad de las Personas) y el acceso gratuito a la documentación de identidad personal.

Asimismo, puede mencionarse que hasta no hace mucho tiempo el estudio y conceptualización del derecho a la identidad, en el ámbito propio del derecho filial, reconocía una bifurcación en identidad estática o dinámica. La primera -que se relaciona más estrechamente con la filiación por naturaleza- prioriza la verdad o realidad biológica y la identificación de una persona, estando conformada por el genoma humano, huellas digitales, fecha y lugar de nacimiento, nombre de progenitores, signos distintivos de una persona. La segunda -que se vincula más a la filiación adoptiva-, se refiere a la construcción de la personalidad de alguien según sus atributos, características y su desempeño en los más diversos ámbitos -religioso, cultural, ético, ideológico, etcétera-, prevaleciendo la historia personal, biografía existencial y los lazos sociales que una persona construye, con prescindencia a que tales vínculos coincidan o no con el de sangre.

Actualmente, esta conceptualización se ha complejizado. En primer lugar, ello obedece a que se ha reconocido en nuestro ordenamiento jurídico el derecho de acceso a técnicas de reproducción humana médicamente asistida, mediante la sanción de la Ley $\mathrm{N}^{\mathrm{o}} 26.862^{3}$ y posteriormente con la sanción del Código Civil y Comercial, en cuyos artículos 560/564 y concordantes se establecen reglas generales relativas a la filiación por técnicas de reproducción humana asistida. Este avance ha implicado que, jurídicamente, debamos desmembrar el concepto de identidad estática, diferenciando a la identidad genética de la biológica. Dicho en otros términos, además del reconocimiento de un vínculo biológico de base, se distingue a la identidad biológica, derivada de quien lleva adelante la gestación del niño, de la identidad genética, que resulta de quien o quienes aportan el material genético para la formación del embrión.

De lo que hasta aquí se viene mencionando se advierte que se ha producido una enorme evolución en el reconocimiento

3 Sancionada el 05/06/2013. 
de la identidad personal como un verdadero derecho humano, así como también se ha complejizado su conceptualización, ampliando su espectro e incluyendo en su denominación nuevos elementos que hasta no hace mucho tiempo eran impensados. A punto tal se ha desarrollado el concepto que se han desmembrado del tronco común (identidad personal) múltiples ramas o derechos derivados, tales como el derecho a conocer los orígenes, el derecho a la información en relación directa a la identidad de las personas, el derecho a un nombre, el derecho a la identificación y a la obtención de los documentos de identidad respectivos, el derecho a tener un vínculo filial, entre otros.

\section{Identidad estática y primacía de la realidad biológica. Regulación de la actividad probatoria en los procesos civil y penal}

En este breve trabajo dejaremos de lado aquellos supuestos de filiación por adopción donde, lógicamente, el emplazamiento filial no responde ni tiene como base a un vínculo de sangre, y los casos de técnicas de reproducción humana asistida, dado que merecen un tratamiento especial. Entonces, partiremos de la base de cualquier supuesto de filiación por naturaleza, donde se intenta proteger la identidad estática, la identidad biológica mediante el establecimiento del verdadero vínculo filial.

El CCyC contiene, además de reglas procesales aplicables a los procesos de familia, disposiciones generales para las acciones de filiación y luego reglas concretas para cada acción en particular. En tal sentido, adopta expresamente el principio de libertad, amplitud y flexibilidad de la prueba (confr. art. 710), todo ello con la finalidad de procurar acercarse lo más posible a la verdad en relación a los hechos controvertidos y, consecuentemente, lograr una satisfacción más plena de los derechos que se ventilan en estos procesos de familia.

Ahora bien, en relación a las acciones de filiación propiamente dichas, el CCyC establece que se admiten toda clase de 
pruebas, incluidas las genéticas, que pueden ser decretadas de oficio o a pedido de parte (artículo 579, primer párrafo).

El principio de libertad en materia probatoria comprende la facultad de las partes de ofrecer, producir, controlar las pruebas que hacen a su derecho y las de la contraria, pero también incluye a la actividad jurisdiccional que puede autorizar -y aún disponer de oficio- su producción por medios probatorios aún no previstos en el código de forma, en virtud del desarrollo científico, por ejemplo, y por no haber existido en la época de sanción de las leyes procesales ${ }^{4}$.

Hoy, la nueva redacción prevista por el CCyC, en el artículo 579 primer y segundo párrafos, en cuanto dispone que, en los procesos de filiación, se admitirán toda clase de pruebas, incluidas las genéticas, prevé una amplitud suficiente para abarcar los avances científicos futuros, que pueden ser decretadas aun de oficio. Asimismo, permite que en caso de imposibilidad de realizar la prueba con alguna de las partes, la misma se realice con material genético de parientes por naturaleza hasta el segundo grado, priorizando los más próximos. Lógicamente, tales previsiones no implican una obligación para el Juez de admitir todas las pruebas propuestas si es que ellas son notoriamente improcedentes por dilatorias, inconducentes en relación a los hechos controvertidos, o inadecuadas en función del objeto procesal.

Ahora bien, además de lo señalado, hemos de preguntarnos ¿cuál es el límite para la procedencia de dichas pruebas? Atento el principio de amplitud probatoria mencionado parecería ser que el límite no está dado por el tipo de prueba en sí mismo sino en el modo de su obtención. Va de suyo que no resultan procedentes las pruebas obtenidas ilícitamente $\mathrm{y}$, paralelamente, el derecho no podría avalar, so pena de llegar

\footnotetext{
4 En materia de filiación, en un principio se ofrecían las denominadas pruebas biológicas, que se circunscribían a las pericias médicas, luego a las investigaciones del sistema de histocompatibilidad (HLA-A, B, C y DR) y análisis de enzimas eritrocitarias y, finalmente, se admitió la tipificación del ADN.
} 
al conocimiento acabado de la verdad, todo procedimiento que importe la comisión de un delito o algún acto ilícito.

Siguiendo dicho lineamiento, podría afirmarse que, según el estado actual del avance científico, siendo la prueba de ADN la más idónea para arribar al conocimiento de la verdad respecto de la existencia o no de vínculo biológico entre dos personas, ella no podría realizarse sin haber recabado previamente el consentimiento de quienes deben someterse a ella. En otras palabras, según las normas vigentes en nuestra legislación civil, para la realización de la prueba pericial genética se requiere inexcusablemente el sometimiento voluntario de los interesados. Para el caso de que tal consentimiento no sea prestado, el ordenamiento establece ciertas consecuencias jurídicas pero no se prevé el sometimiento forzoso o involuntario.

En ese sentido, según lo normado por el artículo 579 del CCyC, "En las acciones de filiación se admiten toda clase de pruebas, incluidas las genéticas, que pueden ser decretadas de oficio o a petición de parte. Ante la imposibilidad de efectuar la prueba genética a alguna de las partes, los estudios se pueden realizar con material genético de los parientes por naturaleza hasta el segundo grado; debe priorizarse a los más próximos. Si ninguna de estas alternativas es posible, el juez valora la negativa como indicio grave contrario a la posición del renuente."

En relación a esta norma pueden realizarse varias apreciaciones. Una de ellas es la relativa al cambio de terminología utilizada, en cuanto el artículo 253 del Código Civil derogado se refería a las pruebas "biológicas", en cambio, la redacción actual alude más específicamente a las "genéticas". Con acierto se ha manifestado que este cambio terminológico responde a la mayor precisión que ostenta la palabra "genética", en relación a que la prueba de A.D.N. es la más precisa para determinar la existencia o inexistencia de vínculo filial.

En segundo lugar, en cuanto a la consecuencia jurídica establecida para el caso de la negativa a someterse a las pruebas genéticas corresponde analizar el antecedente normativo más próximo. Así, La Ley 23.511 de creación del Banco Nacional de 
Datos Genéticos 5 , en su artículo cuarto, establece que "Cuando fuese necesario determinar en juicio la filiación de una persona (...) La negativa a someterse a los exámenes y análisis necesarios constituirá indicio contrario a la posición sustentada por el renuente". Conforme a la postura adoptada por la norma, en caso de que el accionado se niegue a someterse a la realización de la prueba genética, tal negativa debería ser reforzada por alguna otra prueba en sentido concordante, dado que ella por sí sola es sólo un indicio, una mera sospecha, y no constituye prueba contundente como para hacer lugar lisa y llanamente a la demanda.

Distinto sería el caso si la norma creara una presunción legal en contra del renuente. En este caso, si así fuera establecido legalmente, la negativa importaría que, justamente, se presuman ciertos los dichos del accionante relativos a la paternidad en perjuicio del padre alegado reticente, con lo cual no sería necesaria la producción de ninguna otra prueba que los refuerce.

Ahora bien, el CCyC, en el artículo analizado adopta una postura distinta de las dos mencionadas precedentemente, dado que establece que valorará la negativa "como indicio grave contrario a la posición del renuente". Se ha interpretado que el indicio grave "significa que no se necesita, de manera obligatoria o como requisito sine qua non, otra prueba para hacer que tal conducta renuente tenga fuerza y que, por ende, se pueda hacer lugar a la acción de reclamación de filiación (...) No obstante, si se cuenta con prueba hábil para fortalecer la negativa -y, en definitiva, acercarse a la verdad biológica-, ella deba ser incorporada al proceso...".

Claro está que, en todos los casos analizados, se adopta una consecuencia jurídica que resulta incompatible con la verdad

\footnotetext{
5 Sancionada el 13 de mayo de 1987.

6 Código Civil y Comercial de la Nación Comentado, Marisa Herrera, Gustavo Caramelo y Sebastián Picasso. Obtenido de http://www.saij.gob.ar/docs-f/codigo-comentado/ CCyC_Nacion_Comentado_Tomo_II.pdf, .Pág.. 318.
} 
biológica. En otros términos, las distintas soluciones legales mencionadas no garantizan el derecho a la identidad en tanto no permiten que se conozca con rigor científico acerca de la existencia o inexistencia de un vínculo biológico. Contrariamente a ello, puede válidamente entenderse que la consecuencia legal prevista por el artículo 579 tercer párrafo viola lisa y llanamente el derecho a la identidad por no garantizar el acceso efectivo a conocer la verdad sobre el lazo de sangre en cuestión, lo cual únicamente se lograría si la norma legal previera la realización compulsiva o forzosa de la prueba científica de A.D.N.

Resulta de vital importancia lo mencionado precedentemente. No puede soslayarse que, desde el punto de vista psicológico, se ha estudiado que para un niño $-y$, en definitiva, para todo ser humano- es más impactante y le causa mayor sufrimiento la "duda", la "incertidumbre" en relación a quiénes son sus padres, a cuál es su origen, que el directo desconocimiento.

Por su parte, si nos disponemos a analizar la regulación sobre el tema en el ordenamiento que rige el proceso penal, sabemos que la Ley $\mathrm{N}^{0} 26.549^{7}$, que modifica al código procesal penal, incorporó a este cuerpo normativo el artículo 218 bis, en los siguientes términos: "El juez podrá ordenar la obtención de ácido desoxirribonucleico (ADN), del imputado o de otra persona, cuando ello fuere necesario para su identificación o para la constatación de circunstancias de importancia para la investigación. La medida deberá ser dictada por auto fundado donde se expresen, bajo pena de nulidad, los motivos que justifiquen su necesidad, razonabilidad y proporcionalidad en el caso concreto. Para tales fines, serán admisibles minimas extracciones de sangre, saliva, piel, cabello u otras muestras biológicas, a efectuarse según las reglas del saber médico, cuando no fuere de temer perjuicio alguno para la integridad física de la persona sobre la que deba efectuarse la medida, según la experiencia común y la opinión del experto a cargo de la

\footnotetext{
Sancionada el 18 de noviembre de 2009.
} 
intervención. La misma será practicada del modo menos lesivo para la persona y sin afectar su pudor, teniendo especialmente en consideración su género y otras circunstancias particulares. El uso de las facultades coercitivas sobre el afectado por la medida en ningún caso podrá exceder el estrictamente necesario para su realización. Si el juez lo estimare conveniente, y siempre que sea posible alcanzar igual certeza con el resultado de la medida, podrá ordenar la obtención de ácido desoxirribonucleico (ADN) por medios distintos a la inspección corporal, como el secuestro de objetos que contengan células ya desprendidas del cuerpo, para lo cual podrán ordenarse medidas como el registro domiciliario o la requisa personal. (...)”.

Por lo tanto, siempre que se den las condiciones objetivas de procedencia -que surgen de la propia norma- y una vez que la medida esté judicialmente ordenada, la extracción resulta obligatoria respecto del imputado "o de otra persona" (párrafo primero), no así respecto de la víctima, quien podría oponerse a una extracción corporal, no obstante lo cual el juez podría procurarse tal prueba por otros medios (secuestro de objetos, registro domiciliario, requisa, etcétera). Por lo tanto, tratándose del sujeto investigado, aun cuando se alegue que se trata de una medida coercitiva, humillante, que viola su integridad y/o intimidad, igualmente puede ser obligado a someterse a una extracción compulsiva de A.D.N., y dicho acto es plenamente válido procesalmente.

Es decir que, conforme a la normativa procesal civil y penal analizada, el legislador ha brindado respuestas diferentes. En el proceso civil, en caso de reticencia o negativa del padre alegado, la ley establece como consecuencia jurídica que dicha actitud sea considerada como un indicio grave en contra de la posición del renuente. En cambio en el proceso penal, aún en caso de negativa del sujeto investigado, igualmente puede ser sometido a una extracción compulsiva. Cabría entonces preguntarse si existe coherencia entre ambas soluciones legales analizadas, más aún en la consideración de que la acción de filiación intentada en el proceso civil puede desenmascarar un 
verdadero delito -por ejemplo, por supresión y/o suposición de estado civil y de la identidad (conforme artículos 138 a 139 bis del Código Penal argentino)-.

Podría argumentarse que la compulsividad autorizada en el proceso penal se debe a que dicho fuero procura arribar a la verdad real e histórica, a fin de descubrir si se cometió o no un delito, lo cual involucra el interés de la sociedad toda. Sin perjuicio de ello, aún cuando el proceso civil sea un proceso de partes, de instancia privada, en el caso de las acciones de filiación se encuentran implicados derechos humanos fundamentales, protegidos constitucional y convencionalmente y en tales cuestiones, así como en las que comprometen el estado civil de las personas, también hacen al orden público e interesan a toda la comunidad.

Históricamente, la doctrina procesalista señaló que el juez civil, en el marco de un proceso contencioso con contradictorio y con prueba, no es un investigador de la verdad real, sino un facilitador de su producción, conservación y aprovechamiento pleno. Cierto es que la más autorizada doctrina que establece que la misión del juez no es lograr la comprobación de la verdad, que ésta no es el fin del proceso civil y no podría serlo, manifestando que, en todo caso, su cometido es procurar aproximarse limitada y selectivamente a la verdad ${ }^{8}$. Pero sin pretender

8 PEYRANO, Jorge W. "El Juez y la búsqueda de la verdad en el proceso civil", obtenido de http://www.pensamientocivil.com.ar/system/files/eljuezylaverdad.pdf, en fecha 21/12/2017. En dicho artículo expresa “( ...) Ahora bien: ¿puede siempre y en todos los casos el juez civil perseguir infatigablemente la verdad, previa producción adecuada de la prueba correspondiente, 0 , a veces, deberá conformarse con que lo que declara como cierto simplemente debe "ser tenido o aceptado como verdadero" (9) Creemos que el tema se sale de sus cauces adecuados cuando se parte de la premisa de que la misión del juez civil dentro de un proceso contencioso con contradictorio y con producción de prueba, es encontrar la verdad del caso. El magistrado civil no es un investigador a todo trance de la verdad (10), no lo es ni puede serlo. Su cometido, en cambio, es procurar aproximarse limitada y selectivamente a la verdad. Limitadamente porque el ofrecimiento y la producción de la prueba (de la cual depende la obtención de la verdad), están condicionados al accionar de las partes y porque, también, la tarea del Oficio posee límites técnicos infranqueables que ni tan siquiera pueden ser salvados por el uso de medidas para mejor proveer (11); y es selectivo porque es impensable e imposible que un 
contradecir dicha postura, no podemos dejar de resaltar que, paralelamente a ello, se reconoce que existe un "derecho a probar" completado por un derecho a una debida y explicitada valoración de la prueba producida. Todo ello adquiere mayor rigor en el ámbito específico del derecho de familia donde existe un interés de la sociedad en el conocimiento y certeza sobre el status y los atributos de la personalidad de sus integrantes.

Puede concluirse que, frente a la necesidad de garantizar los derechos a la identidad y a conocer los orígenes, íntimamente vinculados a la dignidad misma de todo ser humano, no podría válidamente priorizarse la voluntad del accionado quien puede echar por tierra tales derechos con sólo negarse a someterse a la prueba en cuestión. Más aún cuando, conforme al estado actual del avance de la ciencia, podría afirmarse que la pretendida "vulneración de la integridad física" no es tal. Ello es así dado que hoy en día, una mínima muestra de sangre extraída en un mínimo tiempo es suficiente; pero asimismo, existen métodos alternativos para recolectar A.D.N., tales como el hisopado bucal, o la extracción de cualquier material biológico (cabellos, restos cutáneos, etcétera), y aún -como surge de la norma procesal penal analizada- de "medios distintos de la inspección corporal". Por lo cual, se puede afirmar que en la actualidad, el hecho de que la norma jurídica civil no se garantice la producción de medidas de prueba necesarias para, esclarecer, garantizar el ejercicio efectivo de derechos fundamentales como el derecho a conocer la identidad y los orígenes biológicos, parece ser un mero capricho y, más aún, un verdadero retroceso.

\section{Conclusión}

Entendemos que cuando se encuentran en juego derechos personalísimos del más alto rango como el derecho a la

tribunal (por lo menos en Argentina) en cualquier supuesto se deba empeñar en conseguir la versión fáctica "verdadera". 
identidad y a conocer los orígenes, verdaderos derechos humanos, no resulta acertada la solución legal brindada al caso por el art. 579 del CCyC. Es decir, en tales casos, no resulta "justo" contentarnos con una sentencia judicial basada en una presunción o un grave indicio de que el accionado es el padre biológico del accionante, por el solo hecho de que se negó a realizarse la prueba de $\mathrm{ADN}$, dado que tal solución -el indicio, grave o no- no es prueba acabada de la verdad. Consecuentemente, va de suyo que es factible solicitar la declaración de inconstitucionalidad -o, mejor dicho, de anticonvencionalidad- de dicha norma en razón de que atenta claramente contra la constitución nacional y convencionales internacionales vigentes.

Lo cierto es que, tal como se adelantara “...tanto el indicio como la presunción son posturas que no logran llegar a la verdad sobre el lazo biológico, sino que extraen determinadas consecuencias jurídicas de un determinado comportamiento -como lo es la negativa a someterse a la prueba de ADN-. En otras palabras, solo la compulsividad permite revelar la verdad...".

A la luz del nuevo paradigma imperante de los derechos humanos y su impacto actual, puede concluirse que el artículo 579, tercer párrafo, del CCyC, se encuentra en franca colisión con el artículo 75 inciso 23 de la Constitución Nacional que impone en cabeza de los distintos poderes del estado la obligación de legislar y adoptar medidas de acción positiva que garanticen la igualdad real de oportunidades y de trato y el pleno goce $y$ ejercicio de los derechos reconocidos por la Constitución y los Tratados Internacionales vigentes sobre derechos humanos. Contrariamente a ello, la norma analizada del CCyC adopta la solución legal de considerar "indicio grave" a la posición del renuente a someterse a pruebas de $\mathrm{ADN}$, legitimando en cierta forma dicha negativa y proponiendo una consecuencia jurídica basada en una "ficción jurídica" y no en una certeza derivada de una prueba científica. Por ello, la inclusión de dicho tercer

9 Código Civil y Comercial de la Nación Comentado, Ob. Cit. Pág. 318. 
párrafo al artículo 579 el significa un retroceso y una colisión con las normas constitucionales y convencionales que protegen el derecho humano de la identidad. De lo expuesto se deriva que claramente se puede solicitar la declaración de inconstitucionalidad o anticonvencionalidad del artículo 579, tercer párrafo, del CCyC, o podrá hacérselo aún de oficio, en atención a que la nueva misión del rol de los jueces, en su rol activista y protector, los convierte en jueces de los derechos humanos. 